\title{
EL ARTE COMO POSIBILIDAD DE REPRESENTAR EL HORROR Obras contramonumentales de la memoria traumática \\ 1
}

\section{Art as a Possibility to Represent the Horror}

Traumatic Memory Contramonumentales Works

1 El título completo de la tesis es «La fotografía como representación de la memoria y las tensiones irresueltas el pasado traumático». Fue defendida y aprobada en 2018.
María Paula Núñez | paularte.n@gmail.com

Facultad de Bellas Artes

Universidad Nacional de La Plata

Argentina

Directora: Marcela Andruchow | marcela_andruchow@yahoo.com.ar

Museología. Facultad de Bellas Artes

Universidad Nacional de La Plata. Argentina

Recibido: 19/3/2018

Aceptado: 7/6/2018

\section{RESUMEN}

En este trabajo se analizará la fotografía artística en sus potencialidades para representar la memoria traumática de las víctimas de la dictadura cívico-militar en la Argentina (1976-1983). Se tomarán como casos tres ensayos fotográficos de artistas contemporáneos: Huellas de desapariciones, de Helen Zout; Buena memoria, de Marcelo Brodsky y Arqueología de la ausencia, de Lucila Quieto. Se estudiará el modo en que sus obras, desde procedimientos formales y conceptuales, dan lugar a reflexiones posibles con respecto a la memoria del pasado traumático a partir del concepto de contramonumento.

\section{PALABRAS CLAVE}

Memoria; contramonumento; arte; representación 
La memoria del terrorismo de estado en la Argentina continúa abierta, la violencia dictatorial ha dejado treinta mil desaparecidos y las consecuencias del espanto aún están presentes en la sociedad. En este sentido, nos interesa analizar una serie de obras de arte conmemorativas que, desde su propuesta formal e iconográfica, tienen correspondencias con la noción de contramonumento, y comprender su lugar en la lucha por la construcción de la memoria (Jelin, 2002).

El objetivo principal es analizar fotografías que se proponen hacer representable, legible y pensable el horror (Didi-Huberman, 2015) e indagar el modo en que el lenguaje del arte permite lidiar con las limitaciones implícitas en todo intento de representar acontecimientos de asesinatos masivos (Friedlander, 2007). En las obras Arqueología de la ausencia, de Lucila Quieto: Buena memoria, de Marcelo Brodsky y Huellas de desapariciones, de Helen Zout se explorarán los recursos plásticos y conceptuales a partir de los cuales los artistas buscaron hacer referencia a tiempos pretéritos y abordar la violencia [Figuras 1, 2 y 3]. Asimismo, la reflexión analítica con respecto a estas obras puede resultar un aporte dentro de los estudios culturales de la memoria (Huyssen, 2010), a partir de la interrelación entre memoria, historia y arte y de la profundización en lo que respecta al rol de la fotografía en el terreno de las prácticas conmemorativas.

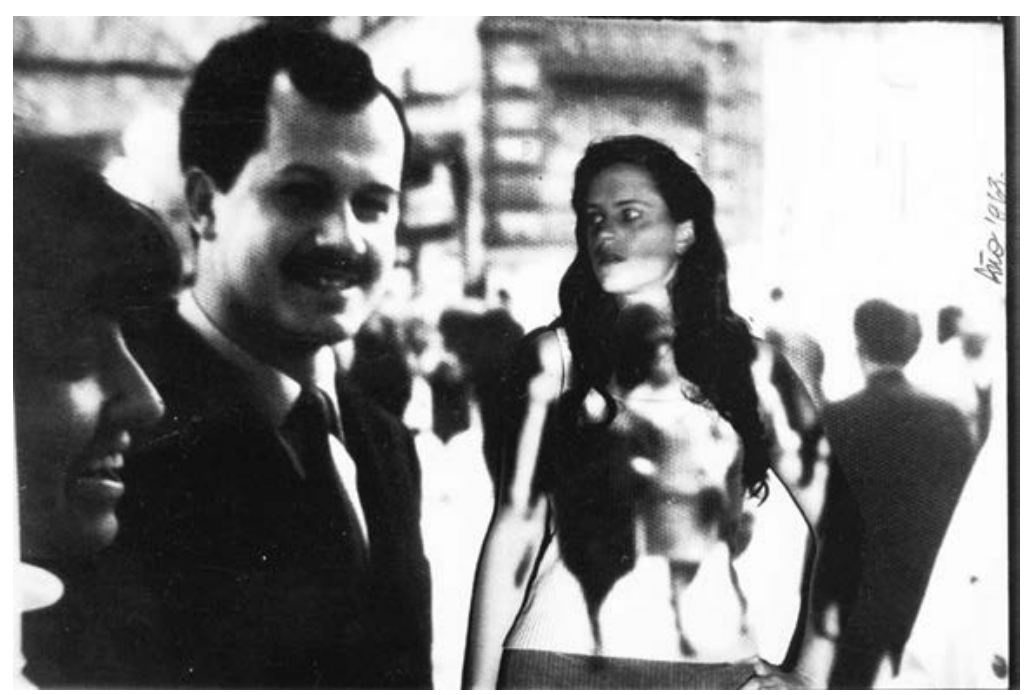

Figura 1. Arqueología de la ausencia (2001), Lucila Quieto. Carlos Alberto Quieto, el padre de Lucila, fue secuestrado en 1976, unos meses antes de que ella naciera 
(2) monumento es entendido como arquetipo históricamente determinado para la rememoración y la materialización de la memoria de acontecimientos o de personajes históricos en el espacio público, vinculado a configuraciones específicas de lo nacional. Son parte de una tradición moderna occidental que adquirió sus antecedentes en la antigüedad clásica y su sentido original ha sido modificado con el tiempo adquiriendo nuevas connotaciones (Andruchow, 2010)

3 Esencialmente, se proponen activar un trabajo de memoria (Jelin, 2002) referido a los hechos traumáticos y a las memorias de las víctimas directas o indirectas; a hechos antiheróicos que surgen como contrarelato de la visión lineal y totalizadora de la historia tradicional (Martínez, 20013)
Nos centraremos en el modo en el que estas representaciones retoman recuerdos de las generaciones afectadas por el terrorismo de estado y habilitan reflexiones en retrospectiva sobre esos sucesos traumáticos. El abordaje de este estudio se centrará en la noción de counter monument (contramonumento) (Young, 2000), con la cual se identifica a una serie de obras conmemorativas que adquieren su sentido oponiéndose a la morfología y a los criterios conmemorativos del monumento tradicional en el espacio público. ${ }^{2}$ Para James Young el monumento presenta al pasado con una retórica realista y una figuración rígida que se contrapone a la naturaleza dinámica de la cultura, sustituye el trabajo de la memoria que debe ser ejercido por la sociedad y obtura la acción rememorativa para siempre liberando a los sujetos de la obligación de recordar. Young destaca un novedoso lenguaje que logra poner en tensión la recepción de las obras y el modo tradicional de entender a la historia y a la memoria sujetas a un cambio semántico. ${ }^{3}$ Domingo Martínez Rosario (2013) retoma estas concepciones con las que define conceptualmente una tipología que nos permite abordar analíticamente propuestas artísticas contramonumentales que circulan en galerías y en salas de museo.

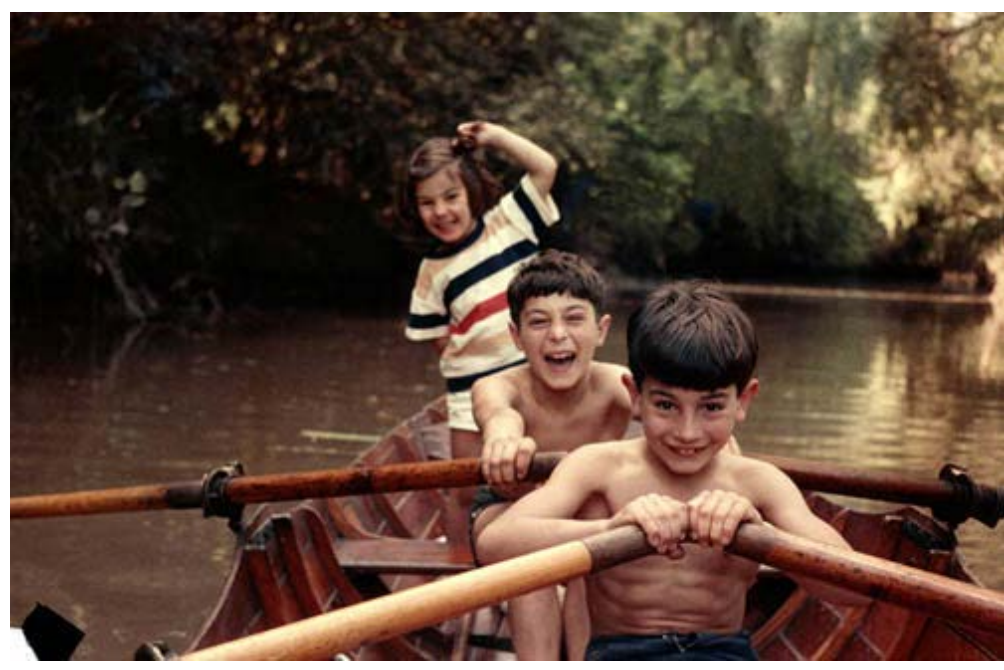

Figura 2. Tres en el bote(2009), Marcelo Brodsky. Brodsky es el del medio, su hermana Andrea está al fondo y en primer lugar está Fernando, su hermano desaparecido en 1979

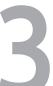




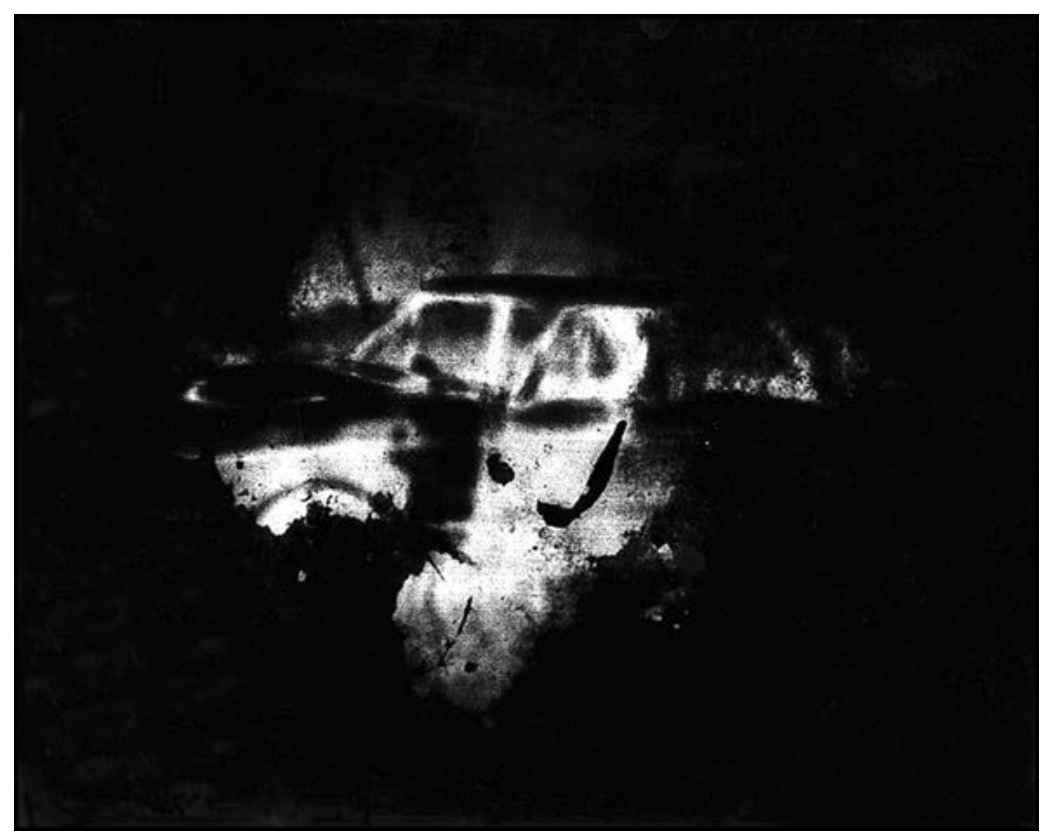

Figura 3. Ford Falcon incendiado con dos personas no identificadas en su interior. Legajo policial de 1976 (2001), Helen Zout

El énfasis de estas propuestas artísticas se caracteriza por la dimensión experiencial que ofrecen al espectador a partir de la utilización de determinados conceptos acentuados desde la materialidad de la obra. Las fotografías proponen un desplazamiento temporal que permite traer eventos remotos y ponerlos en revisión desde el presente. Con su cualidad banal cotidiana, mnemónica y votiva, promueven la empatía en el espectador activando procesos de identificación positiva que logran movilizar el interior. Mediante la elaboración de complejas retóricas y la incorporación de elementos ajenos a la técnica fotográfica, producen un relato que logra infiltrarse en quien visualiza sin atentar contra la buena forma y provocar el rechazo. Al mismo tiempo, son capaces de inquietar, perturbar y suscitar enlaces con una historia terrorífica. El aporte de elementos indiciales, como el texto y los testimonios, orientan una narrativa que abre una complejidad de saberes y de emociones y da lugar a que el espectador pueda prolongar desde su imaginación una acción que no se agota en lo que se muestra o lo que se nombra para hacer pensable y cognoscible el horror. De manera que logran convocar al espectador 
a involucrarse en la reflexión de tensiones irresueltas con el pasado traumático porque no son propuestas cerradas ni tranquilizadoras y no están realizadas para complacer estéticamente sino para desafiar a los sujetos a no olvidar. Son revisiones autorreferenciales de vivencias que permiten introducirnos en la globalidad de un momento de época.

\section{****}

De este modo, es posible afirmar que el contramonumento, en los casos fotográficos seleccionados, se torna un lugar idóneo en el que la memoria puede ser representada, comunicada, compartida, revisada y reelaborada desde una tensión permanente que no deja lugar al olvido social y que promueve la fundación de espacios para la construcción de memorias individuales y colectivas, dinámicas y críticas. Esto permite llegar a las nuevas generaciones con el fin de que puedan abordar la problemática y sus significados, incorporando una relevancia ética para fortalecer el presente y guiar las acciones del futuro.

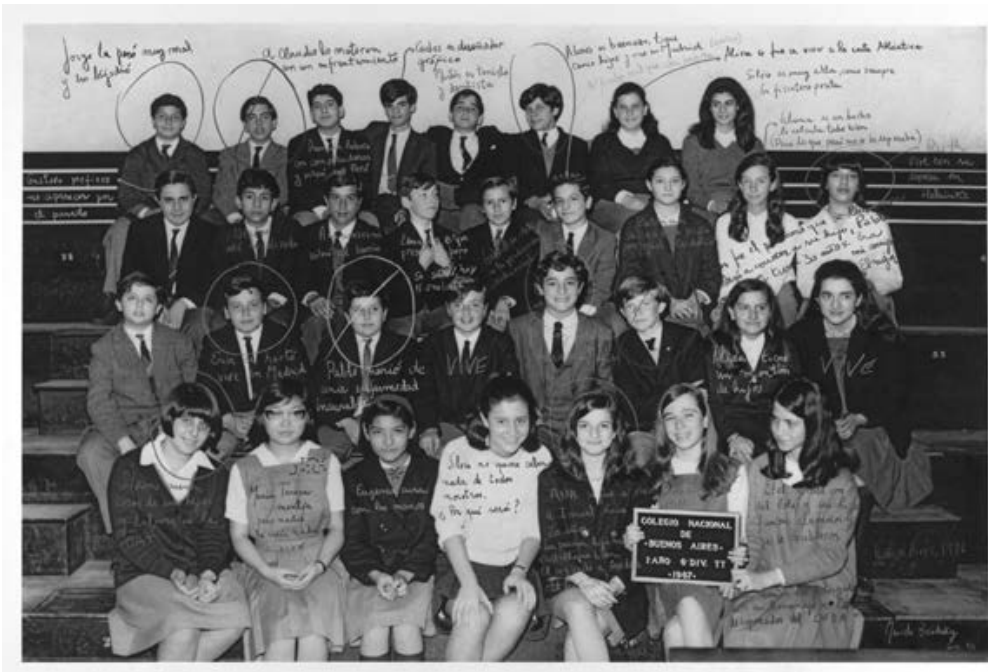

Figura 4. Sexta división del año 1967 (1996), Marcelo Brodsky. Gigantografía

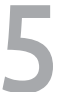




\section{REFERENCIAS}

Didi-Huberman, G. (2015). Remontajes del tiempo padecido: el ojo de la historia. Ciudad Autónoma de Buenos Aires, Argentina: BiblosUniversidad del Cine.

Friedlander, S. (Comp.). (2007). En torno a los límites de la representación. El nazismo y la solución final. Bernal, Argentina: Universidad Nacional de Quilmes.

Huyssen, A. (2010). Esculturas de la memoria de Doris Salcedo. En Modernismo después de la modernidad. Buenos Aires, Argentina: Gelida S.A.

Jelin, E. (2002). Trabajos de Memoria. Madrid, España: Siglo Veintiuno.

Martínez Rosario, D. (2013). La obra de arte como contramonumento. Representación de la memoria antiheroica como recurso en el arte contemporáneo (Tesis de Doctorado). Universidad Politécnica de Valencia, Valencia, España.

Young, J. (2000). Cuando las piedras hablan. Revista puentes, (1), 80-93. Recuperado de http://www.memoriaenelmercosur.educ.ar/wpcontent/uploads/2009/04/puentes01.pdf 